*Este artigo contém parte das discussões realizadas em dissertação de mestrado da autora, intitulada ' $O$ estado e o setor privado de saúde no caminho da desestruturação gradual do SUS', defendida em junho de 2016, no Programa de Pós-Graduação em Desenvolvimento Econômico do Instituto de Economia da Universidade Estadual de Campinas (Unicamp), e orientada pelo Prof. Dr. Eduardo Fagnani.
1 Universidade Estadual de Campinas (Unicamp), Faculdade de Ciências Médicas, Departamento de Saúde Coletiva - Campinas (SP), Brasil.

leticiatravagin@gmail.com

\section{O avanço do capital na saúde: um olhar crítico às Organizações Sociais de Saúde*}

\author{
The onrush of capital in health: a critical look at the Social Health \\ Organizations
}

Letícia Bona Travagin'

RESUMO O objetivo deste artigo foi oferecer uma visão crítica à gestão da saúde pública via Organizações Sociais, entendendo-as como parte do processo de desestruturação da proteção social em um contexto de reforço ao capital. O texto considera a interação entre Estado e capital, as críticas internacional e nacional aos Estados sociais e, sobretudo, uma série de problemas intrínsecos às Organizações Sociais. Metodologicamente, vale-se de revisão e organização de literatura relevante e de textos legislativos. Conclui-se que este mecanismo de gestão consiste em privatização da saúde pública, favorecendo a expansão do setor privado de saúde, em detrimento do sistema público.

PALAVRAS-ChaVe Estado. Organizações em saúde. Política. Privatização. Sistema Único de Saúde.

ABSTRACT The objective of this article was to offer a critical view of public health management through Social Organizations, understanding them as part of a larger process of dismantling of social protection in a context of strengthening of capital. The text considers the interaction between State and capital, the international and national criticism of the Social States, and mainly, several problems intrinsic to Social Organizations. Methodologically, it revised and organized relevant literature and legislation. It is concluded that this management mechanism is the privatization of public health, contributing to the expansion of the private health sector, to the detriment of the public system.

KEYWORDS State. Health organizations. Politics. Privatization. Unified Health System. 


\section{Introdução}

Este trabalho deriva de parte das discussões realizadas em pesquisa de mestrado, na qual se demonstrou que o próprio Estado brasileiro contribui para a expansão do setor privado de saúde, causando a desestruturação gradual e permanente do Sistema Único de Saúde (SUS). A gestão de unidades do SUS por meio de Organizações Sociais de Saúde (OSS) ilustra bem este argumento e, portanto, é o objeto de análise principal deste artigo. Mantendo um olhar crítico à questão, as OSS devem ser situadas em meio a um processo amplo de disputa político-econômica e de ataques à proteção social.

A Reforma Gerencial do Estado de 1995, que inaugurou as Organizações Sociais (OS) no Brasil, veio na esteira de um processo internacional de desmonte dos grandes sistemas de proteção social, no qual as recomendações do Banco Mundial tiveram influência expressiva. O setor privado, fruto do longo histórico privatista da assistência à saúde no Brasil, abraçou a onda neoliberal 'importada' em 1990.

Discutir o contexto político e econômico no qual está inserido o SUS justifica-se pela necessidade de entender as contradições que desfiguraram o projeto cidadão desenhado na Constituição Federal de 1988. A fronteira entre o Estado e o SUS é um espaço acirrado de disputas que têm implicações deletérias ao funcionamento do sistema e, por consequência, à efetivação do direito à saúde.

A transferência de atividades de saúde pública para empresas do terceiro setor não é apenas um arranjo administrativo, mas se trata de uma decisão política situada em contexto capitalista. Ademais, de acordo com Santos (2017), a saúde pública brasileira, inserida na crise política atual, passa por uma fase de possível esgotamento do projeto reformista da redemocratização, que desenhou o SUS. Isso demanda que se repensem os rumos dos movimentos da década de 1980 e que se dedique mais atenção às relações entre Estado e capital. O SUS não é imune ao conservadorismo, classicismo e patrimonialismo do Estado brasileiro.

A literatura sobre a economia política da saúde tem considerado essa perspectiva. Ocké-Reis (2017) recuperou algumas análises críticas ao Estado capitalista, entendendo-o como um subsidiador de atividades privadas de saúde, e que mantém intencionalmente a austeridade fiscal. $\mathrm{O}$ autor também levantou a necessidade de compreensão teórica sobre os problemas do setor de saúde, que ultrapassam o diagnóstico corrente da suposta "ineficiência” do SUS (OCKÉ-REIS, 2017, P. 368).

Mendes (2015) desconstrói o entendimento vulgar de que o Estado é uma instituição neutra e separada do poder econômico. O discurso do 'Estado autônomo' leva ao discurso da 'crise do Estado', ou seja, de que os problemas dos sistemas públicos residem na arquitetura de um Estado que assumiu muitas funções sociais, que gasta muito com políticas públicas, e que, por isso, tornou-se ineficiente. Ao contrário, a relação intrínseca entre Estado e poder econômico indica que a crise da saúde pública brasileira não é apenas 'do Estado', tampouco será remediada com ajustes administrativos, porque é estrutural do modo de produção capitalista, notadamente na sua fase de financeirização acentuada a partir dos anos 1980 (MENDES, 2015, P. 67).

Com tudo isso em vista, este artigo objetiva vincular o advento das OSS no Brasil ao avanço do capital sobre o setor de saúde, com respaldo do Estado. Para isso, utilizaram-se revisão e organização bibliográfica sobre as OSS, o contexto político nacional e internacional, além de análise de alguns textos legislativos. Quanto ao contexto, retoma-se uma breve introdução sobre a constituição e a crítica neoliberal ao Estado e alguns pontos relevantes das publicações do Banco Mundial aplicadas à gestão da saúde na década de 1990. Depois, passa-se à análise da Reforma Gerencial do Estado de 1995, de onde nasceram as OSS no Brasil; e, por fim, à problemática específica das OS na saúde pública. 


\section{Contexto}

A institucionalização de um sistema de saúde único, público, universal e gratuito foi possível graças à canalização das reivindicações do movimento sanitarista para a Constituição Federal promulgada em 1988, tida como 'Constituição cidadã'. A luta dos sanitaristas foi parte da luta pela redemocratização do País. É historicamente relevante o fato de que as forças políticas de resistência à ditadura militar, reivindicadoras da justiça social e dos direitos dos cidadãos, tenham se deslocado para a Assembleia Nacional Constituinte, fazendo deste um momento particular e atípico da história brasileira.

A Constituição de 1988 avançou no que se refere à consolidação de um Estado social no País, com bastante atraso em relação aos países centrais. $\mathrm{O}$ documento tem como um de seus pontos fortes a formulação das diretrizes da seguridade social, presentes nos artigos 194 e 195. Foi a primeira Constituição brasileira a usar o termo 'seguridade social', que supõe o Estado como garantidor do direito universal a um padrão mínimo de vida, independentemente de contribuição prévia.

No entanto, é importante contextualizar os limites dessa passagem no Brasil. Concorda-se com o Behring e Boschetti (2011) ao afirmarem que, no Brasil, não houve uma reforma socialdemocrata nos moldes dos welfare states europeus que, apesar de se manterem capitalistas, assumiram um papel redistributivo. A seguridade social brasileira combinou focalização e universalização, ao invés de reforçar a última. Por isso, usa-se apenas Estado social em referência à experiência brasileira. Aqui, a constituição de fato de um Estado de bem-estar demandaria:

[...] um processo de radicalização e ultrapassagem do Estado burguês, já que elas [as reformas democráticas] podem superar a si mesmas, considerando-se a cultura visceralmente antidemocrática e conservadora da burguesia brasileira. (BEHRING; BOSCHETTI, 2011, P. 151).
Disso decorrem as reações ávidas e rápidas das elites nacionais em relação ao novo sistema de proteção social brasileiro e, por consequência, ao SUS, já em 1990. A tentativa de abraçar algumas políticas solidárias e de reduzir a mercadorização na provisão dos serviços públicos preocupou - e ainda preocupa - a burguesia brasileira. Como agravante, o contexto internacional era absolutamente adverso à seguridade social.

As discussões de Friedrich Hayek, Ludwig Von Mises e Milton Friedman haviam se materializado nas políticas dos governos de Margareth Thatcher (Reino Unido, 1979) e Ronald Reagan (Estados Unidos, 1981). A crise das grandes economias capitalistas nas décadas de 1970 e 1980, após os dois choques do petróleo e a elevação súbita dos juros estadunidenses, foi atribuída às políticas keynesianas e aos 'excessos' dos Estados. Antes enaltecido pelo seu papel no desenvolvimento econômico, o welfare state passou a ser visto como uma ameaça à liberdade da iniciativa privada e tido como 'inchado', 'ineficiente', 'burocrático', 'rígido', 'irresponsável'.

As discussões político-econômicas globais nos anos 1980 voltaram-se para a defesa do chamado Estado mínimo, cujas intenções foram sintetizadas por Bresser-Pereira (2009):

Para o neoliberalismo, o Estado deveria se tornar 'mínimo', e isso significava pelo menos quatro coisas: primeiro, que deixasse de se encarregar da produção de determinados bens básicos relacionados com a infraestrutura econômica; segundo, que desmontasse o Estado social, ou seja, todo o sistema de proteção social por meio do qual as sociedades modernas buscam corrigir a cegueira do mercado em relação à justiça social; terceiro, que deixasse de induzir o investimento produtivo e o desenvolvimento tecnológico e científico, ou seja, de liderar uma estratégia nacional de desenvolvimento; e, quarto, que deixasse de regular os mercados e principalmente os mercados financeiros porque seriam autorreguladOS. (BRESSER-PEREIRA, 2009, P. 8-9) 
O Consenso de Washington, em 1989, oficializou a defesa do Estado mínimo e mudou o tom das recomendações internacionais do Banco Mundial. Concebido como um dos pilares da ordem regulada de Bretton Woods, na década de 1980, o Banco passou a ser elemento fundamental de disseminação da ideologia e políticas econômicas estadunidenses. As publicações do Banco recomendavam políticas sociais consonantes com o ajuste neoliberal e a austeridade fiscal por ele requerida. Ou seja, políticas sociais residuais. Os países latino-americanos foram um alvo especial de seus 'conselhos' porque passavam por um momento de reorganização do bloco no poder após o fim de regimes ditatoriais.

O setor da saúde tornou-se uma pauta relevante para o Banco, que passou a vislumbrar nele uma grande área de investimento de capital (RIZZOTTO, 2015). Nesse contexto, foram produzidos três documentos importantes para a discussão, são eles: 'Brasil: novo desafio à saúde do adulto' (1991); o relatório anual de 1993, dedicado à saúde, 'World Development Report 1993: Investing in Health' (1993); e 'A organização, prestação e financiamento da saúde no Brasil: uma agenda para os anos 90' (1995). A preocupação do Banco com o sistema de saúde brasileiro não se deu por acaso: o país acabava de adotar um sistema de saúde único, universal, público e gratuito.

Uma noção de equidade específica, e diferente daquela contida nas diretrizes do SUS, norteia todos esses documentos. O Banco enaltece a equidade supondo um nivelamento por baixo, ou seja, apenas os mais pobres deveriam ser atendidos pelo Estado porque não têm condições de pagar pelos serviços privados. Em outras palavras, direciona o governo para os pobres e o mercado para as classes de renda média e alta.

Resumidamente, as recomendações gerais do Banco eram: i) reorientação dos gastos públicos em direção à atenção básica apenas aos mais pobres; ii) criação de um ambiente regulatório que permita ao setor privado atuar livremente, incluindo o sistema privado lucrativo; iii) considerar a necessidade de pagamento no setor público pelos usuários com renda acima de um determinado valor; iv) aprofundamento da descentralização do sistema; v) contenção de custos, focalizando-os em procedimentos de alto 'custo-efetividade'; vi) elaboração de mecanismos que limitem o acesso da população ao sistema público; vii) limitar o governo federal às funções de regulação, assistência técnica e pesquisa (BANCO MUNDIAL, 1991, 1993, 1995).

Em termos práticos, a efetivação dessas recomendações passaria por incentivos fiscais ao setor privado, tetos de gastos, redução do número de leitos e tempo de permanência, limitação do acesso à tecnologia, copagamentos, incentivos fiscais aos seguros privados, compra de serviços privados pelo Estado e, o que mais interessa reter aqui, a transferência de atividades para o setor privado (BANCO MUNDIAL, 1995).

A gestão por meio das OS é claramente um mecanismo de transferência de serviços do setor público para o setor privado; e foi introduzida no Brasil justamente nesse momento de crítica aos sistemas de proteção social.

\section{A Reforma do Estado de 1995: crítica brasileira ao Estado social}

Em 1995, logo no início do primeiro mandato de Fernando Henrique Cardoso, iniciou-se o processo de Reforma Gerencial do Aparelho do Estado, elaborada pelo ministro Luiz Carlos Bresser-Pereira, à frente do Ministério da Administração e Reforma do Estado (Mare). O plano diretor da reforma defendia que desde que o Estado assumira o caráter de Estado social, a partir da democratização pós-ditadura, aumentaram sobremaneira as demandas da sociedade e as despesas com políticas sociais. Dada a rigidez do modelo burocrático, o aparelho do Estado não teria mais condições de operar eficientemente. 
A chamada 'crise do Estado' foi definida como uma crise fiscal e, sobretudo, o

esgotamento da estratégia estatizante de intervenção do Estado, a qual se reveste de várias formas: o Estado do bem-estar social nos países desenvolvidos, a estratégia de substituição de importações no terceiro mundo, e o estatismo nos países comunistas. (BRASIL, 1995, P. 11).

Era claramente um discurso de negação à intervenção regulatória do Estado sobre o mercado.

A Constituição de 1988 foi considerada um agravante no processo de 'inchaço' do Estado e um retrocesso em relação à antiga reforma administrativa de 1967, que amenizara a rigidez do Estado burocrático descentralizando algumas atividades estatais, e racionalizara a administração e a condução do orçamento.

Baseado nesses princípios, o plano diretor propôs:

[...] Neste sentido, são inadiáveis: (1) o ajustamento fiscal duradouro; (2) 'reformas econômicas orientadas' para o mercado, que, acompanhadas de uma política industrial e tecnológica, garantam a concorrência interna e criem as condições para o enfrentamento da competição internacional; (3) a reforma da previdência social; (4) 'a inovação dos instrumentos de política social', proporcionando maior abrangência e promovendo meIhor qualidade para os serviços sociais; e (5) a reforma do aparelho do Estado, com vistas a aumentar sua 'governança', ou seja, sua capacidade de implementar de forma eficiente políticas públicas. (BRASIL, 1995, P. 11, GRIFO NOSSO).

Anos depois, Bresser-Pereira (2008) negou que tenha se inspirado no neoliberalismo para elaborar a reforma operada pelo Mare - ideologia que, aliás, consideraria utópica. Sua inspiração teria vindo da reforma gerencial inglesa, nascida da corrente de pensamento chamada de New Public Management
(NPM). Mais uma vez, Bresser insiste em afastar o neoliberalismo, afirmando que o NPM não estava nos planos de Margareth Thatcher; ela apenas aceitara um acordo com servidores públicos e consultores ingleses que puderam dar início à reforma. Por fim, o ex-ministro afirmou não ter recebido qualquer apoio do Banco Mundial, mas do Banco Interamericano de Desenvolvimento (BID). Dentro do Brasil, os grandes apoiadores teriam sido os governadores e prefeitos de grandes cidades que necessitavam de maior flexibilidade para lidar com o funcionalismo público.

Contudo, o discurso que justificou a reforma derivou das críticas internacionais aos welfare states dos países centrais. A versão brasileira da crítica, possivelmente aquém das expectativas dos neoliberais mais ferrenhos, partia do mesmo pressuposto: a ineficiência do Estado. Ela se aproxima também do discurso do Banco Mundial ao afirmar a necessidade de transferência de serviços públicos ao setor privado.

Um dos pilares da reforma foi atribuir formas de propriedades diferentes a cada tipo de atividade realizada pelo Estado. Assim, seria possível transferir atividades antes executadas pelo Estado para um novo setor: 'o setor público não estatal', aquele que executa atividades de interesse público, mas é regulado pelo regime jurídico privado. Esse é o princípio básico da publicização, que está na origem das OS. Em 1997, o Mare publicou cadernos sobre a Reforma do Estado. O caderno intitulado 'Organizações Sociais detalha o processo de publicização e as competências de uma OS' (BRASIL, 1997).

A publicização foi um mecanismo estratégico da reforma, dada a sua capacidade de enxugar as atividades desenvolvidas pelo Estado. O processo consiste em transferir atividades consideradas não exclusivas do Estado para o terceiro setor, o 'setor público não estatal', composto de empresas privadas que executam atividades de interesse público. O Estado limitar-se-ia ao papel de 
regular o sistema e subsidiar financeiramente as empresas contratadas. Segundo o documento, a publicização tornaria mais eficiente e ágil a execução das políticas públicas.

De acordo com os formuladores da Reforma do Estado, as seguintes atividades não são exclusivamente estatais, ou seja, não precisam ser fornecidas pelo Estado e, portanto, sujeitam-se ao processo de publicização: educação, cultura, meio ambiente, pesquisa científica e, o que interessa aqui, a saúde.

Depois de três anos discutindo no Congresso, com o apoio da opinião pública, o cerne do plano diretor foi institucionalizado pela Emenda Constitucional $n^{\circ}$ 19. A partir dela, a 'eficiência' foi incluída como um dos princípios da administração pública (BRASIL, 1998A). Já a institucionalização das OS não foi discutida pela sociedade ou pelos Conselhos das áreas publicizáveis. Elas foram criadas por uma medida provisória (MP no 1.591/1997), um mecanismo do poder executivo, que meses depois foi oficializada pela Lei federal $\mathrm{n}^{\circ}$ 9.637, em 15 de maio de 1998, na qual se definiu:

Art 10: O Poder Executivo poderá qualificar como organizações sociais pessoas jurídicas de direito privado, sem fins lucrativos, cujas atividades sejam dirigidas ao ensino, à pesquisa científica, ao desenvolvimento tecnológico, à proteção e preservação do meio ambiente, à cultura e à saúde, atendidos aos requisitos previstos nesta Lei. (BRASIL, 1998B, N. P.).

Como uma forma de aproximar o 'cidadão-cliente' dos serviços e de cumprir o suposto controle social das atividades da OS, ficou estabelecido na lei que $20 \%$ a $30 \%$ dos membros do conselho administrativo da OS deveriam vir da sociedade civil. Além disso, a entidade contratada deveria apresentar relatórios periódicos à entidade supervisora demonstrando os resultados atingidos e as respectivas prestações de contas. A lei reafirma também que a OS qualificada e contratada por meio de um contrato de gestão deve respeitar três diretrizes:
I - ênfase no atendimento do cidadão-cliente; II - ênfase nos resultados, qualitativos e quantitativos nos prazos pactuados; III - controle social das ações de forma transparente. (BRASIL, 1998B, N. P.).

Quanto aos contratos de gestão, instrumento que firma a parceria entre a OSS e o poder público, depois de elaborados conjuntamente pelo órgão supervisor e a OS, devem ser aprovados pelos ministros ou autoridades das áreas em questão. Por fim, a absorção por OS de atividades desenvolvidas por órgãos públicos pode incluir a cessão de bens móveis, imóveis e recursos humanos às OS, que estão dispensadas de licitações e concursos públicos.

\section{Organizações Sociais de Saúde e ameaça ao SUS}

O mecanismo de gestão da saúde por OSS dificulta a implantação plena do SUS no Brasil, eximindo o Estado da responsabilidade de garantir a assistência à saúde. Esta perspectiva tem sido reafirmada por pesquisadores e docentes defensores da saúde pública (ANDREAZZI; BRAVO, 2014; ANDREAZZI; BRAVO; PACHECO, 2015; CARNEIRO JUNIOR; ELIAS, 2006; LIMA; BRAVO, 2015; MELO; TANAKA, 2001; PENTEADO FILHO, 1998).

Em primeiro lugar, é possível questionar a constitucionalidade das OSS. A Lei Orgânica da Saúde (BRASIL, 1990) prevê que o SUS contrate organizações sem fins lucrativos em caráter complementar, a fim de ampliar a oferta de serviços quando esgotadas as instalações públicas de administração direta. As OSS, entretanto, não são complementares, e sim substitutivas da gestão estatal, que é afastada da atividade em questão após a celebração do contrato de gestão. A suposta parceria entre o Estado e a OSS na verdade trata-se de uma transferência de atividades e recursos do público para o privado. É uma privatização disfarçada de parceria.

Como são reguladas pelo direito privado, 
as OSS têm autonomia de processos e dispensa de licitação, contratam seus funcionários por meio da Consolidação das Leis do Trabalho (CLT) e não estão submetidas aos tribunais de contas públicas; contudo recebem dinheiro público. Além da contradição mais evidente - recebem dinheiro público, mas operam em condições de mercado - há indícios de outros problemas, dentre os quais se destaca a alta rotatividade dos contratos de trabalho e a "quarteirização”, que ocorre quando a OSS subcontrata outra empresa privada para realizar atividades-meio, mecanismo que lhes é permitido (ANDREAZZI; BRAVO, 2014, P. 507). Como são entidades sem fins lucrativos, também estão isentas do pagamento de imposto de renda e das contribuições sociais (Contribuição Social sobre o Lucro Líquido - CSLL, Contribuição para o Financiamento da Seguridade Social Cofins e Contribuição Patronal).

A transferência de servidores públicos para as OSS é um ponto especialmente problemático porque pode envolver afastamento de um cargo adquirido por concurso público. Isso conflita com um dos eixos da Lei Orgânica da Saúde, expresso no art. 27., que é a formação e valorização dos recursos humanos do sistema (BRASIL, 1990). Na prática, cada estado e município tem autonomia para elaborar legislação que dispõe sobre as OSS e definir como o poder executivo deve proceder com a transferência dos servidores. O estado de São Paulo, o primeiro a legislar sobre as OSS, seguiu os termos gerais da Lei federal $n^{\circ} 9.637 / 98$.

Artigo 16 - Fica facultado ao Poder Executivo o afastamento de servidor para as organizações sociais, com ônus para a origem. \$1-- Não será incorporada aos vencimentos ou à remuneração de origem do servidor afastado qualquer vantagem pecuniária que vier a ser paga pela organização social. §2ำ - Não será permitido o pagamento de vantagem pecuniária permanente por organização social a servidor afastado com recursos provenientes do contrato de gestão, ressalvada a hipótese de adicional relativo ao exercício de função temporária de direção e assessoria. (SÃO PAULO, 1998, P. 2).

Outro problema grave está no fato de que por trás de algumas OSS estão grandes empresas do setor de saúde. O Sírio Libanês, com unidades em São Paulo e Brasília, que atende clientes de dezenas de planos de saúde, mantém uma instituição de responsabilidade social qualificada como OSS, o Instituto de Responsabilidade Social SírioLibanês (IRSSL). O Instituto é qualificado como OSS pelo estado de São Paulo e pela capital, gerindo cinco estabelecimentos de saúde, incluindo hospitais importantes.

A Rede D'Or São Luiz, presente em quatro estados e responsável pelos luxuosos hospitais Copa D'Or e Barra D'Or no Rio de Janeiro, entre outros, também mantém uma OSS, o Instituto D'Or, gestor do Hospital Estadual da Criança.

Além de OSS derivadas de empresas antigas e consolidadas no ramo da saúde, a proliferação desse mecanismo tem feito surgir empresas especializadas em gerir contratos de gestão como OSS. Um exemplo disso é o Instituto de Atenção Básica e Avançada à Saúde (Iabas), fundado em 2008, que já conta com cerca de 8.000 funcionários e é responsável por 69 serviços de saúde apenas no município de São Paulo, segundo informações contidas no site da empresa.

Vale lembrar que a Lei complementar 1.131, de 2010, do estado de São Paulo, permitiu aos hospitais estaduais geridos por OSS a possibilidade de utilizarem até $25 \%$ das suas instalações para atendimentos privados, com ou sem plano de saúde (ANDREAZZl; BRAVO, 2014). Felizmente, essa decisão foi considerada inconstitucional pelo Tribunal de Justiça do Estado de São Paulo (TJ-SP). Contudo, vê-se como os estados e municípios têm flexibilidade para legislar sobre as OSS. Nesse caso, tratar-se-ia de instalações de saúde públicas, com investimento do Estado, usadas para atendimentos privados mediante pagamento 
do usuário ou plano de saúde. Não há garantias de que uma decisão como essa não seja tomada em outras localidades.

Este ponto leva a outro. Não há garantia de que uma entidade privada, mesmo sem fins lucrativos, tenha algum interesse socialmente justo pela saúde pública. Como elas são autônomas para administrarem os recursos humanos e financeiros, estão sujeitas a favorecimentos pessoais e comportamentos patrimonialistas. Elas podem, por exemplo, oferecer salários exorbitantes a diretores e muito baixos aos enfermeiros - lembrando, com dinheiro público. A privatização do sistema de saúde precariza os termos de trabalho e fere um dos eixos estruturais do SUS, a valorização dos seus recursos humanos.

Como devem atingir metas de resultados, mas não devem explicações sobre os processos, não é impossível que essas entidades fraudem relatórios, a fim de justificar os recursos arrecadados. Andreazzi e Bravo (2014) relatam que no Distrito Federal o Ministério Público identificou ilegalidades, como falta de planilhas de custo, improbidade administrativa, pendências com o Tribunal de Contas e, inclusive, salários muito altos a diretores. Em 2016, o jornal 'O Globo' veiculou a notícia de que oito OSS que operavam na cidade do Rio de Janeiro eram investigadas por suspeita de irregularidades que incluíam desvios de recursos públicos e superfaturamento de compras. Nesse caso, o Tribunal de Contas afirmava que o principal problema seria justamente a fragilidade da fiscalização dos contratos de gestão (O GLOBO, 2016).

Argumenta-se que o Estado deve supervisionar as atividades das OS, mas a fiscalização é realmente frágil. Embora a legislação nacional sobre as OSS preveja o envio de relatórios periódicos às entidades estatais de controle, os detalhes desse acordo ficam por conta do contrato de gestão. Como foi dito, há muita flexibilidade nas decisões legais sobre as OSS. Os contratos de gestão variam entre os estados e municípios, ou seja, não há um padrão nacional de fiscalização.
Carneiro Júnior e Elias (2006) analisaram os métodos de controle de duas OS em São Paulo, detectando o descumprimento da lei: em entrevista, um deputado estadual afirmou que as OSS deveriam encaminhar um relatório para a comissão reguladora, mas não o fazem. Pahim (2009) investigou contratos com OSS e similares no estado de São Paulo e concluiu que o governo estadual paulista não conseguiu estabelecer uma lógica de fiscalização dos resultados e parâmetros de avaliação. Andreazzi e Bravo (2014, P. 506) citam uma auditoria técnica do Tribunal de Contas do município de São Paulo, na qual consta que a prefeitura não teve controle do dinheiro enviado às empresas em 2009: mais de 1,4 bilhão de reais. Cunha (2016), com base em 30 contratos firmados com a prefeitura de São Paulo entre 2006 e 2014, concluiu que o discurso sobre fiscalização soava eficaz nos textos, mas o acompanhamento efetivo ainda não estava consolidado.

Por englobar várias das questões problemáticas citadas, sobressai o estudo coordenado pela professora Maria Inês Bravo, em 2015, no município do Rio de Janeiro. Envolvendo pesquisadores da Universidade do Estado do Rio de Janeiro (Uerj) e da Universidade Federal do Rio de Janeiro (UFRJ), o projeto Novas Articulações entre o Público e o Privado no Sistema de Saúde Brasileiro: O Caso do Município do Rio de Janeiro teve como um de seus objetivos específicos o entendimento da privatização da rede de saúde carioca por meio de OS.

Quanto aos resultados publicados em Lima e Bravo (2015), destacam-se: i) entre 2009 e 2013, a prefeitura do Rio celebrou contratos com 14 OSS que somam aproximadamente $\mathrm{R} \$ 4$ bilhões; ii) há grandes volumes de recursos concentrados em poucas empresas, com destaque para a empresa Iabas; iii) gastos excessivos em algumas unidades de saúde geridas por OSS, em relação a outras unidades de administração direta da Secretaria Municipal; e, iv) irregularidades, como salários exorbitantes a diretores das 
empresas, inconsistências no processo de qualificação de empresas como OSS, além de superfaturamento em orçamentos de serviços e remédios.

Outra contribuição da pesquisa foi a elaboração de uma tipologia das OSS do Rio de Janeiro, ratificando que esse modelo tem sido interessante para empresas antigas no setor de saúde, para grupos empresariais e para empresas que nasceram especificamente para atuar como OS. Segundo os autores, há cinco tipos de OS atuando no Rio:

1) Orgãos públicos como Fundações de Apoio ou mantenedoras que atuam também como OS $[\ldots] ; 2)$ Entidades filantrópicas de saúde tradicionais que se diversificam para também atuar como OS [...]; 3) Organizações não governamentais que se constituem no período neoliberal para ocupar espaços de execução de políticas públicas, em geral de assistência social, de combate a pobreza, a violência urbana e aproveitam oportunidades abertas pelo setor de saúde com as OS [...]; 4) Organizações não governamentais que se criam especificamente para atuarem como OS [...]; 5) Entidades sem fins lucrativos ligadas a grupos empresariais que também aproveitam oportunidades abertas pelo setor de saúde com as OS, integrando o conjunto de empresas do grupo. (ANDREAZZl; BRAVO; PACHECO, 2015, P. 65).

Tendo essas considerações em vista, o modelo de OSS parece não contribuir para o controle social e estatal do sistema de saúde, como foi defendido na reforma de 1995. Também não se pode supor que os mecanismos de mercado atuem como democratizantes das políticas públicas. As instituições carregam traços da formação social e política da sociedade em questão. $\mathrm{O}$ segmento privado de saúde consolidou-se durante o regime militar, no sistema conhecido como 'medicina previdenciária', e manteve-se forte mesmo após a promulgação da Constituição de 1988. A saúde no Brasil tem um forte caráter privatista.
Quando o Estado transfere serviços a empresas do setor privado de saúde, as elites associadas a este setor ganham espaço de intervenção nas decisões públicas, reforçando práticas clientelistas. Caso se queira construir um processo decisório democrático e, por conseguinte, uma política de saúde inclusiva, é necessário prezar pela integridade e pelo controle popular das instituições estatais. Arretche (1997) expressa essa ideia:

[...] Neste sentido, não há uma relação necessária entre descentralização e redução do clientelismo: este pode ocorrer em qualquer escala de operações. Na verdade, a redução do clientelismo supõe a construção de instituições que garantam a capacidade de enforcement do governo e a capacidade de controle dos cidadãos sobre as ações deste último. (ARRETCHE, 1997, P. 149).

A Lei de Responsabilidade Fiscal de 2000 foi um incentivo a mais para estados e prefeituras adotarem o modelo de OSS, ao limitar as despesas com recursos humanos a $50 \% \mathrm{da}$ receita corrente líquida para a União e a $60 \%$ para estados e municípios. Ela é um mecanismo importante para sustentar ajustes fiscais recessivos e, portanto, afeta diretamente a execução das políticas sociais. Nos últimos anos, sobretudo a partir de 2014, o discurso de austeridade fiscal tem tido protagonismo nas campanhas eleitorais de todos os níveis de governo. Esse contexto pede que os pesquisadores e gestores da saúde pública dediquem mais atenção à privatização disfarçada da saúde, em especial para as OSS, que é um mecanismo de implantação rápida.

Embora haja uma compreensão global do problema, ainda resta esmiuçá-lo, o que demanda investigações atualizadas em nível estadual e municipal. Além da necessidade de preencher as lacunas na compreensão sobre o processo de privatização via OS nos estados e municípios, a conjuntura recente exige resistência ao avanço do capital na saúde pública, visto que se atravessa um 
período intenso de austeridade fiscal, leniência para com o conglomerado econômico da saúde e desmonte deliberado do SUS.

A produção do conhecimento acerca do problema e suas relações com o modo de produção é fundamental, mas não suficiente. Ocké-Reis (2017) acertadamente coloca os desafios estratégicos, políticos e programáticos ao lado do desafio teórico. Isso significa organizar formas de ação sobre e nos sistemas, envolvendo reformas - no sentido redistributivo do termo - na regulação do setor privado, a ampliação do financiamento do SUS e, indispensavelmente, a reconstrução da base social de apoio à saúde pública, e sua respectiva representação parlamentar.

\section{Conclusões}

O modelo de gestão da saúde pública por meio das OSS, longe de ser apenas um recurso administrativo, responde a um processo maior e internacional de desmonte dos sistemas de proteção social. Trata-se de uma forma de privatização e expansão do setor privado de saúde respaldada pelo próprio Estado brasileiro e seus níveis de governo. Aqui, consideram-se as OSS como elementos do setor privado, apesar da sua classificação oficial como 'setor público não estatal' porque elas são reguladas pelo direito privado e estão isentas das obrigações aplicáveis às instituições públicas.

Embora o ex-ministro Bresser-Pereira
(2008) negue a associação entre a Reforma do Aparelho do Estado, de 1995, e as recomendações do Banco Mundial, o processo de publicização atende a elas ao diminuir o papel do Estado na gestão da saúde e transferir atividades ao setor privado. Ainda que não tenha havido apoio direto, o modelo de gestão da saúde por meio das OS é compatível com a sugestão do Banco quanto a transferir um volume maior da assistência à saúde ao setor privado e a reduzir o papel do Estado à regulação do sistema. Ademais, a Reforma de 1995 e as considerações do Banco partem do mesmo diagnóstico: a 'ineficiência' do Estado social.

O problema de desmonte do SUS é de caráter político, e, portanto, a solução não virá de ajustes administrativos pontuais acompanhados de políticas econômicas restritivas. A questão sine qua non reside na maneira pela qual se faz política no Brasil, nos lobbies, no voto mercantilizado, nos interesses econômicos perversos das elites e das coalizões nos três poderes. Não há muitas possibilidades de efetivação da seguridade social em geral, e do SUS em particular, sem que haja reestruturações basais, democráticas e redistributivas, na política e na economia. Caso contrário, o elemento de disputa entre o público e o privado permanecerá manifestando-se em forma de captura do Estado pelo mercado, o que, no caso do setor de saúde pública brasileiro, corrobora a desestruturação gradual e permanente do SUS. 


\section{Referências}

ANDREAZZI, M. F. S.; BRAVO, M. I. S. Privatização da gestão e Organizações Sociais na atenção à saúde. Trabalho, educação e saúde, Rio de Janeiro, v. 12, n. 3, p. 499-518, 2014.

ANDREAZZI, M. F. S.; BRAVO, M. I. S; PACHECHO, J. Novos agentes econômicos fomentados pela contrarreforma liberal na saúde: um panorama das Organizações Sociais atuantes no Município do Rio de Janeiro, Brasil. In: BRAVO, M. I. S. et al. (Org.). A mercantilização da saúde em debate: as Organizações Sociais no Rio de Janeiro. Rio de Janeiro: UERJ - Rede Sirius, 2015. p. 61-67.

ARRETCHE, M. O mito da descentralização como indutor de maior democratização e eficiência das políticas públicas. In: GERSCHMAN, S.; VIANNA, M. L. W. (Org.). A miragem da pós-modernidade: democracia e políticas sociais no contexto da globalização. Rio de Janeiro: Fiocruz, 1997, p. 127-152.

BANCO MUNDIAL. Brasil: novo desafio à saúde do adulto. Washington: Banco Mundial, 1991.

A organização, prestação e financiamento da saúde no Brasil: uma agenda para os anos 90. Washington: Banco Mundial, 1995.

World Development Report 1993: Investing in

Health. Washington, DC: Banco Mundial. Nova Iorque: Oxford University Press, 1993.

BEHRING, E. R.; BOSCHETTI, I. Política social no Brasil contemporâneo: entre a inovação e o conservadorismo. In: BEHRING, E. R.; BOSCHETTI, I. Política social: fundamentos e história. 9. ed. São Paulo: Cortez Editora, 2011. p. 147-164.

BRASIL. Emenda Constitucional n. 19, de 4 de junho de 1998. Modifica o regime e dispõe sobre princípios e normas da Administração Pública, servidores e agentes políticos, controle de despesas e finanças públicas e custeio de atividades a cargo do Distrito Federal, e dá outras providências. Diário Oficial [da] República Federativa do Brasil, Brasília, DF, 5 jun. 1998a. Seção 1, p. 1.
. Lei n. 8.080, de 19 de setembro de 1990. Dispõe sobre as condições para a promoção, proteção e recuperação da saúde, a organização e o funcionamento dos serviços correspondentes e dá outras providências. Diário Oficial [da] República Federativa do Brasil, Brasília, DF, 20 set. 1990. Seção 1, p. 1.

. Lei n. 9.637, de 15 de maio de 1998. Dispõe sobre a qualificação de entidades como organizações sociais, a criação do Programa Nacional de Publicização, a extinção dos órgãos e entidades que menciona e a absorção de suas atividades por organizações sociais, e dá outras providências. Diário Oficial [da] República Federativa do Brasil, Brasília, DF, 18 mai. 1998b. Seção 1.

Ministério da Administração Federal e Reforma do Estado. Organizações Sociais. Cadernos MARE da Reforma de Estado. Brasília, DF, 1997. Disponível em: <http://www.bresserpereira.org.br/Documents/ MARE/OS/caderno2.pdf >. Acesso em: 19 out. 2017.

Ministério da Administração Federal e Reforma do Estado. Plano Diretor da Reforma do Aparelho do Estado. Brasília, DF, 1995. Disponível em: <http://www. biblioteca.presidencia.gov.br/publicacoes-oficiais/catalogo/fhc/plano-diretor-da-reforma-do-aparelho-do-estado-1995.pdf>. Acesso em: 19 out. 2017.

BRESSER-PEREIRA, L. C. Assalto ao Estado e ao mercado, neoliberalismo e teoria econômica. Estudos Avançados, São Paulo, v. 23, n. 66, p. 7-23, 2009.

Os primeiros passos da reforma gerencial do Estado de 1995. Revista Brasileira de Direito Público, Belo Horizonte, v. 6, n. 23, p. 145-186, out./dez. 2008.

CARNEIRO JÚNIOR, N.; ELIAS, P. E. Controle público e equidade no acesso a hospitais sob gestão pública não estatal. Revista de Saúde Pública, São Paulo, v. 40, n. 5, p. 914-920, out. 2006.

CUNHA, A. C. N. M. F. As organizações sociais de saúde na cidade de São Paulo e a efetivação do direito fundamental à saúde. 2016. 152 f. Dissertação (Mestrado em Direitos Humanos) - Faculdade de Direito, 
Universidade São Paulo, São Paulo, 2016.

O GLOBO. Das dez OSs que operam no município, oito estão sob investigação. O Globo. 2016. Disponível em: <https://oglobo.globo.com/rio/das-dez-oss-que-operam-no-municipio-oito-estao-sob-investigacao-18494571>. Acesso em: 26 maio 2017.

LIMA, J. B.; BRAVO, M. I. S. O percurso do financiamento das Organizações Sociais no município do Rio de Janeiro. In: BRAVO, M. I. S. et al. (Org.). A mercantilização da saúde em debate: as Organizações Sociais no Rio de Janeiro. Rio de Janeiro: UERJ - Rede Sirius, 2015. p. 53-60.

MELO, C.; TANAKA, O. As Organizações Sociais no setor saúde: inovando as formas de gestão? Organizações \& Sociedade, Salvador, v. 8, n. 22, p. 1-12, set./dez. 2001.

MENDES, A. N. A saúde pública brasileira no contexto da crise do Estado ou do capitalismo? Saúde e Sociedade, São Paulo, v. 24, supl.1, p. 63-78, 2015.

OCKÉ-REIS, C. O. Desafios da reforma sanitária na atual conjuntura histórica. Saúde em Debate, Rio de Janeiro, v. 41, n. 113, p. 365-371, abr./jun. 2017.

PAHIM, M. L. L. Organizações Sociais de Saúde do Estado de São Paulo: inserção privada no SUS e gestão financeira do modelo pela Secretaria de Estado da Saúde. 2009. 154 f. Tese (Doutorado em Medicina
Preventiva) - Faculdade de Medicina, Universidade de São Paulo, São Paulo, 2009.

PENTEADO FILHO, P. A. Desafios e oportunidades da Reforma do Estado no Brasil: a questão das Organizações Sociais. Organizações \& Sociedade, Salvador, v. 5, n. 11, p. 153-168, 1998.

RIZZOTTO, M. L. F. O Banco Mundial e o sistema nacional de saúde no Brasil. In: PEREIRA, J.; PRONKO, M. (Org.). Demolição de Direitos: um exame das políticas do Banco Mundial para a educação e a saúde (19802013). Rio de Janeiro: Fiocruz, 2015, p. 255-274.

SANTOS, N. R. Conjuntura atual: instigando a busca de rumos e o que fazer. Saúde em Debate, Rio de Janeiro, v. 41, n. 113, p. 353-364, abr./jun. 2017.

SÃO PAULO (Estado). Lei Complementar no 846, de 04 de junho de 1998. Dispõe sobre a qualificação de entidades como organizações sociais e dá outras providências. Diário Oficial [do] Estado de São Paulo, Poder Executivo, São Paulo, SP, 5 jun. 1998. Seção 1.

Recebido para publicação em maio de 2017

Versão final em setembro de 2017

Conflito de interesses: inexistente

Suporte financeiro: Conselho Nacional de Desenvolvimento

Científico e Tecnológico (CNPq) - Processo 130761/2014-1 